\title{
Powered Stapling Platforms in Laparoscopic Liver Resection
}

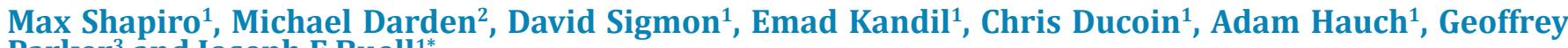 \\ Parker $^{3}$ and Joseph F Buell ${ }^{*}$ \\ ${ }^{1}$ Department of Surgery, Tulane and the Louisiana State University School of Medicine, USA \\ ${ }^{2}$ Department of Economics, Tulane University, USA
}

${ }^{3}$ Tuck School of Business Administration at Dartmouth, USA

Received: September 22, 2017; Published: October 06, 2017

*Corresponding author: Joseph F Buell, Director Tulane Transplant Institute, Tulane University and Louisiana State University, 1415 Tulane Avenue, New Orleans, Louisiana, USA

\begin{abstract}
Introduction: The most recent innovation in laparoscopic surgery has been the introduction of powered stapler platforms. These systems were designed to standardize staple formation, by minimizing tissue dissection and controlling tissue compression and staple formation.
\end{abstract}

Methods: Retrospective cohort analysis compared laparoscopic powered E-beam stapler platform to a laparoscopic non-powered I-beam stapler. The analysis was performed using a robust 2:1 control group study. Statistical analysis was performed using STATA.

Results: Forty-three powered cantilever E-beam stapler resection cases were compared to 86 cases of non-powered I-beam stapler resections. Both cohorts were equally matched for demographics, extent of liver disease, tumor size and type of resection. The non-powered I-beam group did have a higher ASA score (2.8 vs. 2.6; p<0.037). Staple usage, blood loss, and complication rates were equivalent. Operative time was significantly shorter in the powered stapler group (136 vs. $157 \mathrm{hrs}$; $\mathrm{p}=0.026$ ) realizing accumulative 90 -day global cost savings of $\$ 8,248.89$ per case $(\mathrm{p}=0.012)$.

Conclusion: Laparoscopic powered E-beam stapler platforms appear to be safe and efficacious with equivalent performance and complication profiles compared to non-powered I-beam platforms. Powered stapling platforms also appear to minimize parenchymal injury reducing operative time further decreasing disposable and global costs.

Keywords: Liver Resection; Stapler Hepatectomy; Powered Stapler Platforms

\section{Introduction}

Hepatic resection is a technique driven procedure that has evolved over the last half century. Initial experiences in the mid seventies relied on crushing and clamping of the liver parenchyma and its vascular bundles. This technique was often variable and imprecise resulting in significant intraoperative blood loss and postoperative morbidity and mortality [1-3]. Over the next several decades, significant improvements in the understanding of hepatic anatomy, the use of liver anesthetic and surgical techniques, as well as improved instrumentation dramatically reduced operative mortality from $25 \%$ down to nearly $2 \%$ [4-6]. The most recent technical innovation in hepatic resection has been the introduction of the laparoscopic approach. The greatest challenge in this procedure has been the hemostatic and effective transection of liver parenchyma [7-9].
The initial descriptions of laparoscopic liver resection were premised on replicating traditional open surgical techniques utilizing a laparoscopic approach including crush, clamp and clip and CUSA dissection [10-12]. During this time an alternative open approach was introduced by Büchler and reported a large series of hepatic resections employing endovascular staplers to transect the liver parenchyma $[13,14]$. This technique was quickly adopted in the performance of laparoscopic liver resection. Stapler division is now routinely achieved through the use of linear endo staplers employing a hybrid cantilever mechanism with a E-beam construction cutting blade for parenchymal division. Disposable staples are deployed though several size cartridges with a variety of staple heights corresponding to the thickness of the intended tissue. As the endostapler is engaged into the liver, the parenchyma is compressed and the staples interlaced with the critical structures. 
The E-beam then compresses the staples to form a locking secure B-shaped form.

This locking mechanism encompassing the critical structures in the liver parenchyma insuring hemostatic closure. Büchler's initial study confirmed stapler hepatectomy could be performed safely and efficaciously in open hepatic resection. Concurrently our group initiated our experience with laparoscopic stapler hepatectomy. Subsequently, our group performed a multiinstitutional study evaluating laparoscopic stapler hepatectomy compared to electrosurgical transection namely the use of bipolar, harmonic, ligasure and tissue link. In this study of 699 patients, stapler hepatectomty had significant benefits including decreased operative time, blood loss, hospital stay, decreased cost, while incurring equivalent complication rates [15].

As with most surgical devices, stapler technology continues to evolve with the newest and most innovation being anendo vascular powered stapling platform [16-18]. Powered stapling was designed with the intent of improve control through a more stable platform, precise control of the end effectors, reductions in tissue dissection, and more uniformed staple formation with a controlled closure minimizing leak without a decrease in homeostasis [19]. This study evaluates our initial clinical experience with this platform. We examined this technique for clinical performance and identification of potential patient and financial benefits of a powered platform in laparoscopic liver resection when compared to a more traditional non-powered endovascular I-beam stapler.

\section{Materials and Methods}

This is a retrospective cohort study examining two sequential cohorts of laparoscopic liver resections performed by a single surgeon between August 2010 and September 2015. These resections were performed far into the learning curve after 350 prior laparoscopic liver resections. This study was approved by the Institutional Review Board. The study cohort was extracted from a database of 703 hepatic resections. The study cohort was created using our first 43 laparoscopic resections that employed the Echelon Flex powered cantilever E-beam stapler Ethicon, Cincinnati, $\mathrm{OH}$. The comparison group was constructed from the immediately consecutive and prior cohort that underwent hepatic resection with the Endo-GIA a non-powered I-beam-type stapler Covidien, Norwalk, CT.

The control group of non-powered stapler was constructed using a 2:1 control group to provide a robust comparison group. This approach was elected due to the limited number of study cases limiting the employment of a case matched cohort. Patient demographic data and risk factors were collected including: age, gender, race, obesity, diabetes, cirrhosis, ASA status, tumor size, and extent of resection. Clinical outcome data collected included operating room time, estimated blood loss, transfusions, surgical margins, complications, grade of complications, length of stay, readmissions and cost data. Independent variables were evaluated by univariate and multivariate analysis. Further outcome analysis was performed to determine the significant variables impacting complications and readmission. Significant level was set as $\alpha=0.05$. All analyses were performed using STATA.

\section{Results}

Forty-three patients who underwent hepatic resection with the powered E-beam endostapler were compared to eighty-six patients who underwent hepatic resection with the non-powered I-beamtype endostapler. The two groups were well matched without significant differences in demographic data or risk factors between the two cohorts except for a higher ASA score (2.8 vs. 2.6; $\mathrm{p}<0.037$ ) in the I-beam group (Table 1). Clinical outcomes were equivalent in stapler usage, blood loss, transfusions, surgical margins, incidence and grade of complications, reoperations and readmissions (Table 2). However, operative time was significantly shorter in the powered stapler group (129.6 vs. 154.2 mins; $\mathrm{p}=0.026$ ). Multivariate analysis for complications after laparoscopic liver resection identified operating room time (OR 1.5; $p=0.067$ ) and transfusion (OR 3.1; $\mathrm{p}=0.052$ ) were all significant predictors of post-operative complications. Multivariate analysis for readmission failed to identify any predictors of readmission due to low number of patients (Table 3). Financial analysis identified powered stapling platforms provided a cost benefit in operative disposables, OR time, total hospital and 90-day expenses (Table 4).

Table 1: Patient's demographics and risk factors.

\begin{tabular}{|c|c|c|c|}
\hline & Non-Powered I-Beam & Powered E-Beam & P-value \\
\hline Number of Patients & 86 & 43 & \\
\hline Age (years) & $56.5 \otimes 14.6$ & $58.1 \otimes 14.3$ & 0.572 \\
\hline Male Gender (\%) & $39.5 \bowtie 0.52$ & $41.9 \bigotimes 0.56$ & 0.802 \\
\hline Medicaid/Medicare (\%) & $50.0 \otimes 0.50$ & $48.8 \otimes 0.51$ & 0.902 \\
\hline African American Race (\%) & $46.5 \bowtie 0.56$ & $30.2 \bowtie 0.52$ & 0.078 \\
\hline BMI & $28.7 \bigotimes 6.22$ & $29.4 \bigotimes 4.19$ & 0.493 \\
\hline Obesity (\%) & $31.4 \otimes 0.47$ & $44.2 \otimes 0.50$ & 0.155 \\
\hline Hypertension (\%) & $52.2 \varangle 0.50$ & $58.1 \otimes 0.50$ & 0.527 \\
\hline Diabetes (\%) & $19.8 \otimes 0.40$ & $30.2 \bowtie 0.46$ & 0.188 \\
\hline Cancer (\%) & $50.0 \otimes 0.50$ & $34.9 \bowtie 0.48$ & 0.105 \\
\hline Cirrhosis (\%) & $26.7 \otimes 0.45$ & $23.3 \otimes 0.43$ & 0.672 \\
\hline INR & $1.0 \bigotimes 0.09$ & $1.0 \bigotimes 0.06$ & 0.654 \\
\hline
\end{tabular}




\begin{tabular}{|c|c|c|c|}
\hline Creatinine & $1.1 \otimes 0.91$ & $1.0 \otimes 0.49$ & 0.539 \\
\hline Bilirubin & $0.6 \bigotimes 0.41$ & $0.7 \otimes 0.35$ & 0.308 \\
\hline Platelet & $218.8 \bigotimes 75.50$ & $232.4 \otimes 81.90$ & 0.353 \\
\hline Ascites (\%) & $5.8 \otimes 0.24$ & $0.0 \bigotimes 0.0$ & 0.108 \\
\hline ASA & $2.8 \bowtie 0.55$ & $2.6 \otimes .58$ & 0.037 \\
\hline Major Resection (\%) & $11.6 \bowtie 0.32$ & $14.0 \otimes 0.35$ & 0.708 \\
\hline Tumor Size (cm) & $5.0 \otimes 3.9$ & $5.5 \otimes 3.5$ & 0.448 \\
\hline
\end{tabular}

Table 2: Post-operative findings, complications, and outcomes.

\begin{tabular}{|c|c|c|c|}
\hline & Non-Powered I-Beam & Powered E-beam & P-value \\
\hline Number of Patients & 86 & 43 & \\
\hline Staples Used & $10.7 \bigotimes 6.02$ & $10.8 \otimes 4.04$ & 0.864 \\
\hline Estimated Blood Loss (mL) & $168.0 \otimes 244.34$ & $141.9 \otimes 134.04$ & 0.514 \\
\hline Transfusion Rate (\%) & $17.4 \otimes 0.38$ & $7.0 \otimes 0.26$ & 0.108 \\
\hline Complication Rate (\%) & $22.1 \otimes 0.42$ & $20.9 \otimes 0.41$ & 0.881 \\
\hline Mean Clavien-Dindo Grade & $0.6 \otimes 1.14$ & $0.4 \otimes 0.75$ & 0.206 \\
\hline ICU Admission Rate (\%) & $26.7 凶 0.54$ & $11.9 \otimes 0.50$ & 0.104 \\
\hline Bile Leak Rate (\%) & $0.0 \bigotimes 0.00$ & $0.0 \otimes 0.00$ & 1.000 \\
\hline Operating Room Time (hours) & $2.6 \rrbracket 1.13$ & $2.2 \rrbracket 0.50$ & 0.026 \\
\hline
\end{tabular}

Table 3: Multi variate analysis for complication.

\begin{tabular}{|c|c|c|}
\hline Complications & OR & P-value \\
\hline Operating Room Time & 1.541 & 0.067 \\
\hline Transfusion Rate & 3.114 & 0.052 \\
\hline
\end{tabular}

Table 4 : Cost of I-Beam and Powered Plat form staplers in laparoscopic liver resection.

\begin{tabular}{|c|c|c|c|}
\hline & Non-Powered I-Beam & Powered E-Beam & P-value \\
\hline Disposables & $\$ 3,356.40 \rrbracket \$ 1793.56$ & $\$ 1,986.72 \llbracket \$ 688.35$ & $<0.001$ \\
\hline OR Time & $\$ 30,542.65 \rrbracket \$ 17,32.47$ & $\$ 25,693.30 \rrbracket \$ 7818.57$ & 0.026 \\
\hline Total Hospitalization & $\$ 41,286.61 \rrbracket \$ 18,659.18$ & $\$ 32,979.59 \llbracket \$ 8413.34$ & 0.006 \\
\hline 90-Day Cost & $\$ 42,740.10 \rrbracket \$ 19,953.51$ & $\$ 34,491.89 \bigotimes \$ 10,135.27$ & 0.012 \\
\hline
\end{tabular}

\section{Discussion}

Despite often visceral criticism of stapler hepatectomy, this technique has been shown in open and laparoscopic resection to be safe and efficacious [15,20-22]. When compared to traditional resection techniques, stapler hepatectomy provides several distinct advantages over crush and clamp, CUSA and previously defined electrosurgical resection. These include a stable platform, easily deployed with reproducible staple formation resulting in decreased operating room time, decreased blood loss, and shorter length of stays, translating into cost benefits with no significant increase in adverse events [15,20-22]. The current study is the first analysis of new powered platforms used for laparoscopic liver resection. Powered stapling was designed to resolve issues in reliable and reproducible staple height formation.

The conversion to a powered platform resulted inprecise control of end effectors, reductions in collateral tissue dissection, and uniform staple formation with a controlled closure minimizing leak without a decrease in homeostasis [16-18]. Similar to our earlier study of staple hepatectomy, power platform stapling was found to reduce operative times, decrease disposable costs, and overall costs. In this study, power stapling provided no further statistically significant decreases in estimated blood loss, complication rates, and complication grades, length of stay, readmission rates, or margin sizes between the two stapler types. One notable criticism of staple hepatectomy has been staple line failure and in powered stapling platforms the presence of an end articulation tip motion at the completion of blade excursion [16]. The next generation platform has directly addressed this issue by regulating compression and reconfiguring the stapling platform track prohibiting tissue extrusion that resulting in later displacement and failure of complete staple B formation. Powered platform staplers have also been further modified for powered vascular stapling with finer and narrower blade with greater articulation and decreased end articulation motion. This includes the retooling of current power driven platforms realizing $26 \%$ thinner shafts, $26 \%$ narrower anvils, and 11\% greater manual articulation compared to the Endo-GIA, while providing an $83 \%$ reduction in tip movement during tissue transection [16]. 


\section{Conclusion}

Powered stapling platforms appear to provide a significant advantage in insuring reproducible compression, staple height and proper B formation. While the potential increased expense of such technology cannot be dismissed, the increased cost of the powered stapler platform can easily be absorbed by reduction in operating room time cost and ninety-day hospital expenses. In the current challenged environment of governmental health policy such as the Affordable Care Act, value based benefits of new technologies must be vetted prior to widespread adoption [23-25]. This initial examination of powered stapling platforms in laparoscopic liver resection supports the value of this technology.

\section{References}

1. Foster JH (1970) Survival after liver resection for cancer. Cancer 26(3): 493-502

2. Ong GB, Lee NW (1957) Hepatic resection. Br J Surg 62(6): 421-430.

3. Fortner JG, Kim DK, Maclean BJ, Barrett MK, Iwatsuki S, et al. (1978) Major hepatic resection for neoplasia: personal experience in 108 patients. Ann Surg 188(3): 363-371.

4. Fong Y, Cohen AM, Fortner JG, Enker WE, Turnbull AD, et al. (1997) Liver resection for colorectal metastases. J Clin Oncol 15(3): 938-946.

5. Jenkins LT, Millikan KW, Bines SD, Staren ED, Doolas A (1997) Hepatic resection for metastatic colorectal cancer. Am Surg 63(7): 605-610.

6. Emond J, Wachs ME, Renz JF, Kelley S, Harris H, et al. (1995) Total vascular exclusion for major hepatectomy in patients with abnormal liver parenchyma. Arch Surg 130(8): 824-830.

7. Buell JF, Koffron AJ, Thomas MJ, Rudich S, Abecassis M, et al (2005) Laparoscopic liver resection. J Am Coll Surg 200(3): 472-480.

8. Buell JF, Cherqui D, Geller DA, O Rourke N, Iannitti, et al. (2009) World Consensus Conference on Laparoscopic Surgery. The international position on laparoscopic liver surgery: The Louisville Statement, 2008. Ann Surg 250(5): 825-830.

9. Wakabayashi G, Cherqui D, Geller DA, Buell JF, Kaneko H, et al. (2015) Recommendations for laparoscopic liver resection: a report from the second international consensus conference held in Morioka. Ann Surg 261(4): 619-629.

10. Cherqui D, Husson E, Hammoud R, Malassagne B, Stéphan F, Bensaid S, et al. (2000) Laparoscopic liver resections: a feasibility study in 30 patients. Ann Surg 232(6): 753-762.

11. Cai XJ, Yu H, Liang X, Wang YF, Zheng XY, et al. (2006) Laparoscopichepatectomy by curettage and aspiration. Experiences of 62 cases.Surg Endosc 20(10): 1531-1535.
12. Castaldo ET, Earl TM, Chari RS, Gorden DL, Merchant NB, et al. (2008) A clinical comparative analysis of crush/clamp, stapler, and dissecting sealer hepatic transection methods. HPB (Oxford) 10(5): 321-326.

13. Schemmer P, Bruns H, Weitz J, Schmidt J, Büchler MW (2008) Liver transection using vascular stapler: a review. HPB (Oxford) 10(4): 249252.

14. Schemmer P, Friess H, Dervenis C, Schmidt J, Weitz J, et al. (2007) The use of endo-GIA vascular staplers in liver surgery and their potential benefit: a review. Dig Surg 24(4): 300-305.

15. Buell JF, Gayet B, Han HS, Wakabayashi G, Kim KH, et al. (2013) Evaluation of staplerhepatectomy during a laparoscopic liver resection. HPB 15(11): 845-850.

16. Satoh Y, Hayashi S, Yamazaki H, Mikubo M, Naito M, et al. (2014) Ultra powered stapling system for general lung surgery. Kyobu Geka 67(3): 225-228.

17. Licht PB, Ribaric G, Crabtree T, Lanuti M, Molins L, et al. (2015) Prospective Clinical Study to Evaluate Clinical Performance of a Powered Surgical Stapler in Video-assisted Thoracoscopic Lung Resections. Surg Technol Int 27: 67-75.

18. Frattini F, Amico F, Rausei S, Boni L, Rovera F, et al (2015). Current Developments and Unusual Aspects in Gastrointestinal Surgical Stapling. Surg Technol Int 27: 97-101.

19. Sherwinter DA, Gupta A, Cummings L, Eckstein JG (2010)Evaluation of a modified circular stapler for use as a viscerotomy formation and closure device in natural orifice surgery. Surg Endosc. 24(6): 1456-1461.

20. ORourke N, Fielding G (2004) Laparoscopic right hepatectomy: surgical technique. J Gastrointest Surg 8(2): 213-216.

21. Belli G, Fantini C, D Agostino A, Belli A, Cioffi L, et al. (2006) Laparoscopic left lateral hepatic lobectomy: a safer and faster technique.J Hepatobiliary Pancreat Surg 13(2): 149-154.

22. Schemmer P, Friess H, Hinz U, Mehrabi A, Kraus TW, et al. (2006) Staplerhepatectomy is a safe dissection technique: analysis of 300 patients.World J Surg 30(3): 419-430.

23. Savlid M, Strand AH, Jansson A, Agustsson T, Söderdahl G, et al. (2013) Transection of the liver parenchyma with an ultrasound dissector or a stapler device: results of a randomized clinical study.World J Surg 37 (4): 799-805.

24. Schwarz C, Klaus DA, Tudor B, Fleischmann E, Wekerle T, et al. (2015) Transection Speed and Impact on Perioperative Inflammatory Response - A Randomized Controlled Trial Comparing Stapler Hepatectomy and CUSA Resection. PLoS One 10(10).

25. Cassatly MG (2012) The four critical drivers of healthcare reform. J Med Pract Manage 28(3): 162-163.

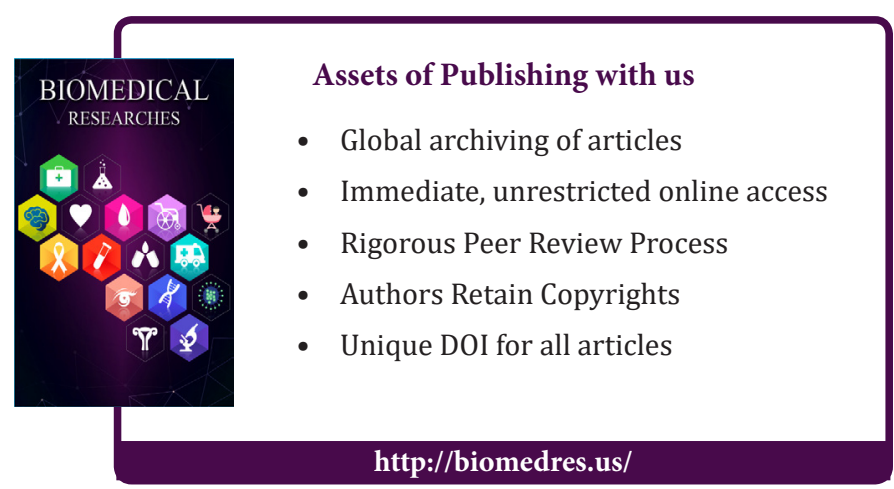

